\title{
Sex Steroid and Growth Factor Profile of a Meningioma Associated with Pregnancy
}

\author{
Justin S. Smith, Alfredo Quiñones-Hinojosa, Miranda Harmon-Smith, \\ Andrew W. Bollen, Michael W. McDermott
}

\begin{abstract}
Background: Increased growth of meningiomas during pregnancy as well as postpartum clinical regression of symptoms have been reported but remain poorly understood. A better understanding of the factors that contribute to these observations, including potential factors associated with pregnancy, could enable design of more effective adjuvant therapies. Methods: We describe the presentation of a meningioma during the immediate postpartum period. Serial imaging demonstrated subsequent rapid decrease in size of the tumour prior to any intervention. The lesion was resected, and the tissue was subjected to immunostaining for gene products associated with pregnancy, including estrogen receptor (ER), progesterone receptor (PR), platelet-derived growth factor receptor B (PDGFRB), fibroblastic growth factor receptor 2 (FGFR-2), epidermal growth factor receptor (EGFR) and human placental lactogen (hPL). Results: The lesion proved to be an atypical fibroblastic meningioma grade II (WHO). Immunostaining demonstrated significant staining for PR, PDGFRB, and FGFR-2. No specific staining for ER, EGFR, or hPL was identified. Conclusion: Although clinical regression of meningioma following pregnancy is well-recognized, imaging data are much less abundant. This report provides clear clinical and imaging documentation of a meningioma associated with pregnancy. In addition, the growth factor profile of this tumour suggests the importance of PR, PDGFRB, and FGFR-2 as potential therapeutic targets.
\end{abstract}

RÉSUMÉ: Profil des hormones stéroïdiennes sexuelles et de l'hormone de croissance d'un méningiome au cours d'une grossesse. Introduction: Une augmentation de la croissance de méningiomes pendant la grossesse ainsi qu'une régression clinique post-partum des symptômes ont déjà été rapportés. Cependant la compréhension de ces phénomènes demeure limitée. Une meilleure compréhension des facteurs qui contribuent à ces observations, particulièrement de facteurs pouvant être associés à la grossesse, pourrait aider au développement de meilleurs traitements adjuvants. Méthodes: Nous décrivons l'évolution d'un méningiome pendant la période immédiate du post-partum. L'imagerie en série a montré une diminution rapide de la taille de la tumeur avant toute intervention. La lésion a été enlevée et soumise à un immunomarquage pour des substances associées à la grossesse, dont les récepteurs des oestrogènes $(\mathrm{RO})$, le récepteur de la progestérone $(\mathrm{RP})$, le récepteur $\mathrm{B}$ du facteur de croissance dérivé des plaquettes (PDGFRB), le récepteur 2 du facteur de croissance fibroblastique (FGFR-2), le récepteur du facteur de croissance épidermique (EGFR) et l'hormone lactogène placentaire humaine (hLP). Résultats: La lésion a été classifiée comme un méningiome fibroblastique de grade II (OSM). À l'immunomarquage, on a observé une coloration importante pour le RP, le PDGFRB et le FGFR-2 et aucune coloration pour le RO, l'EGFR ou le hLP. Conclusion: Bien que la régression clinique des méningiomes après la grossesse soit bien connue, il y a peu de données sur son imagerie. Cet article présente le tableau clinique et l'imagerie d'un méningiome associé à une grossesse. De plus, le profil des facteurs de croissance de cette tumeur suggère que le RP, le PDGFRB et le FGFR2 pourraient être des cibles thérapeutiques importantes.

Can. J. Neurol. Sci. 2005; 32: 122-127

Meningiomas are thought to arise from the arachnoidal cells of the leptomeninges and comprise approximately $15 \%$ of all primary intracranial neoplasms in adults. ${ }^{1}$ These tumours are mostly slow growing, and the majority of them may be cured by surgical resection. A subset of meningiomas, however, demonstrates malignant behavior or cannot be completely
From the Department of Neurological Surgery (JSS, AQH, MHS, MWM) and Department of Pathology (AWB), University of California at San Francisco, San Francisco, California USA

ReCeived April 2, 2004. AcCeptedinfinalform August 19, 2004 Reprint requests to: Justin S. Smith, Department of Neurological Surgery, University of California, San Francisco, 505 Parnassus Avenue, Room M-779, Box 0112, San Francisco, CA, 94143-0112 USA 


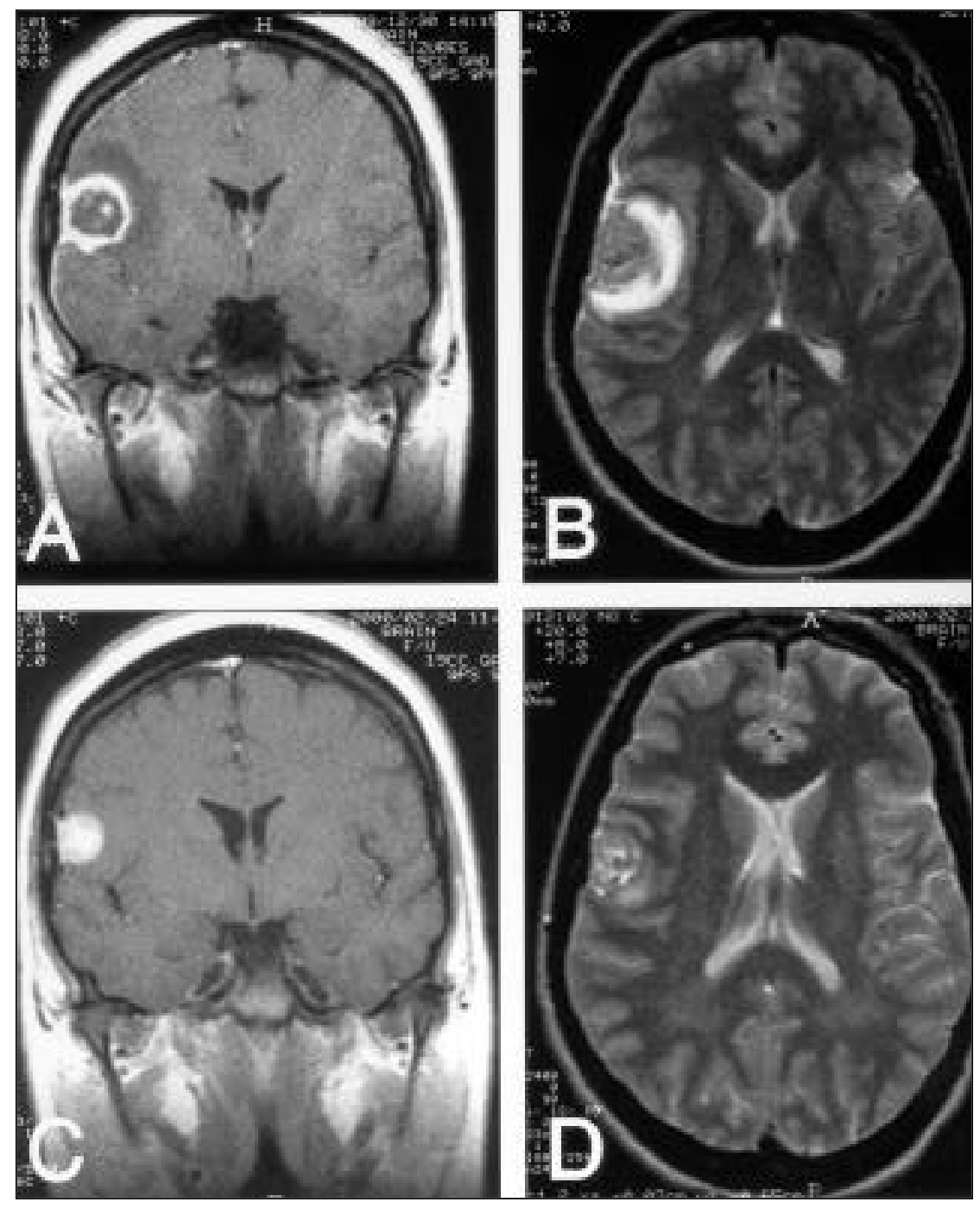

Figure 1: Magnetic resonance (MR) imaging. Coronal Tl-weighted MR image (WI) with contrast $(A)$ and axial T2-WI (B) at original presentation. Coronal T1-WI with contrast and axial T2-WI four months later, just prior to surgery ( $C$ and $D$, respectively).

resected due to their location. ${ }^{2}$ In these cases, radiotherapy remains the standard treatment, since no medical therapy has been found to be clearly effective. A better understanding of the mechanisms by which meningiomas develop and progress may facilitate the development of more effective and directed nonsurgical therapies.

There is considerable evidence to suggest that the growth of meningiomas may be related to sex steroid hormones. Meningiomas are two to three times more common in women than in men., ${ }^{3,4}$ Increased growth has been shown during pregnancy and during the luteal phase of the menstrual cycle..$^{5-7}$ Menopausal women have a greatly reduced risk of developing meningiomas. ${ }^{8}$ An association between breast cancer and meningioma occurrence has been suggested by several studies. ${ }^{9,10}$ Furthermore, progesterone receptors (PR) have been found in $50-80 \%$ of human meningiomas, ${ }^{11-17}$ and meningiomas expressing high levels of PR have a better prognosis and a higher survival rate. ${ }^{11,13,14}$ However, the mechanisms by which sex steroid hormones contribute to meningioma growth remain poorly understood.

We describe a patient who presented immediately postpartum with a seizure and a right frontal cerebral mass, later diagnosed as a meningioma. Subsequent imaging demonstrated a substantial decrease in size of the lesion, suggesting that factors associated with pregnancy had precipitated the patient's presentation and may have been responsible for the postpartum regression observed both clinically and radiographically. Surgically resected tumour tissue was assayed for PR, estrogen receptors (ER), epidermal growth factor receptors (EGFR), platelet-derived growth factor receptor B (PDGFRB), fibroblast growth factor receptor 2 (FGFR-2), and human placental lactogen (hPL). Clinical regression of meningioma in the postpartum period is well-recognized, but imaging data are limited. This case provides clear clinical and radiographic documentation of meningioma regression following delivery, as well as an immunohistochemical assessment of multiple growth factors. 


\section{CaSe Report}

A previously healthy 33-year-old woman (G-3, P-2) presented in labor at 38-4/7 weeks of pregnancy to a community medical center. Her pregnancy had been complicated only by a marginal previa with bleeding at 20 weeks that had since resolved. She underwent a repeat cesarean section without complication and delivered a healthy female infant. On the third postoperative day, the patient had a first time focal motor seizure involving the face and tongue. Head CT and subsequent MRI scans were obtained at that time and revealed a $2.8 \mathrm{~cm}$ cystic ringenhancing lesion that appeared to involve the right frontal parenchyma, with extensive meningeal enhancement over the right cerebral hemisphere (Figure 1A \& 1B). Multiple small discrete calcifications within the brain consistent with cysticercosis were also identified. Given these calcifications, the right frontal lesion was thought to most likely represent a neurocysticercosis cyst with acute inflammation; however, the possibility of a neoplasm could not be excluded. The patient was started on anticonvulsant medication, exhibited no further seizure activity and was referred to our institution for further evaluation.

The patient was seen at our institution approximately seven weeks postpartum. At that time she had remained seizure free, and her neurologic examination was normal. Given the results of her imaging studies and that her clinical history was one of improvement, it was the impression at that time that the frontal lesion most likely represented an inflammatory reaction secondary to cysticercosis. However, since the possibility of a neoplastic process remained, a repeat head MRI scan was obtained four months later (approximately six months postpartum). The

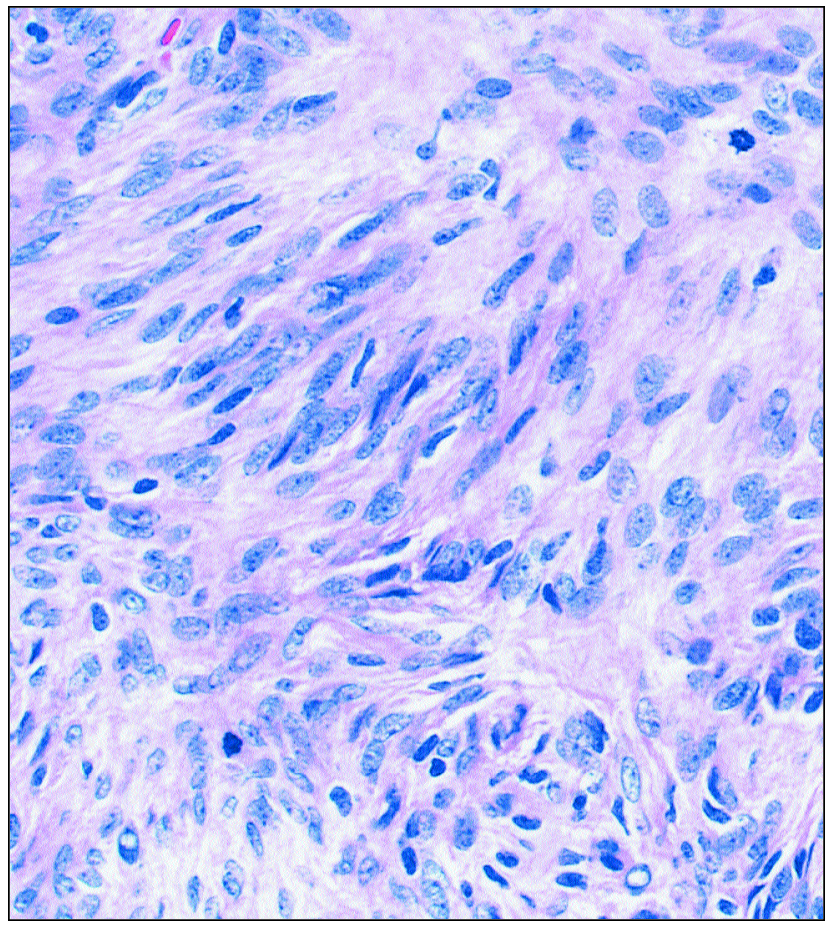

Figure 2: Atypical meningioma with two mitoses in this high power field $(H \& E, 400 X)$.

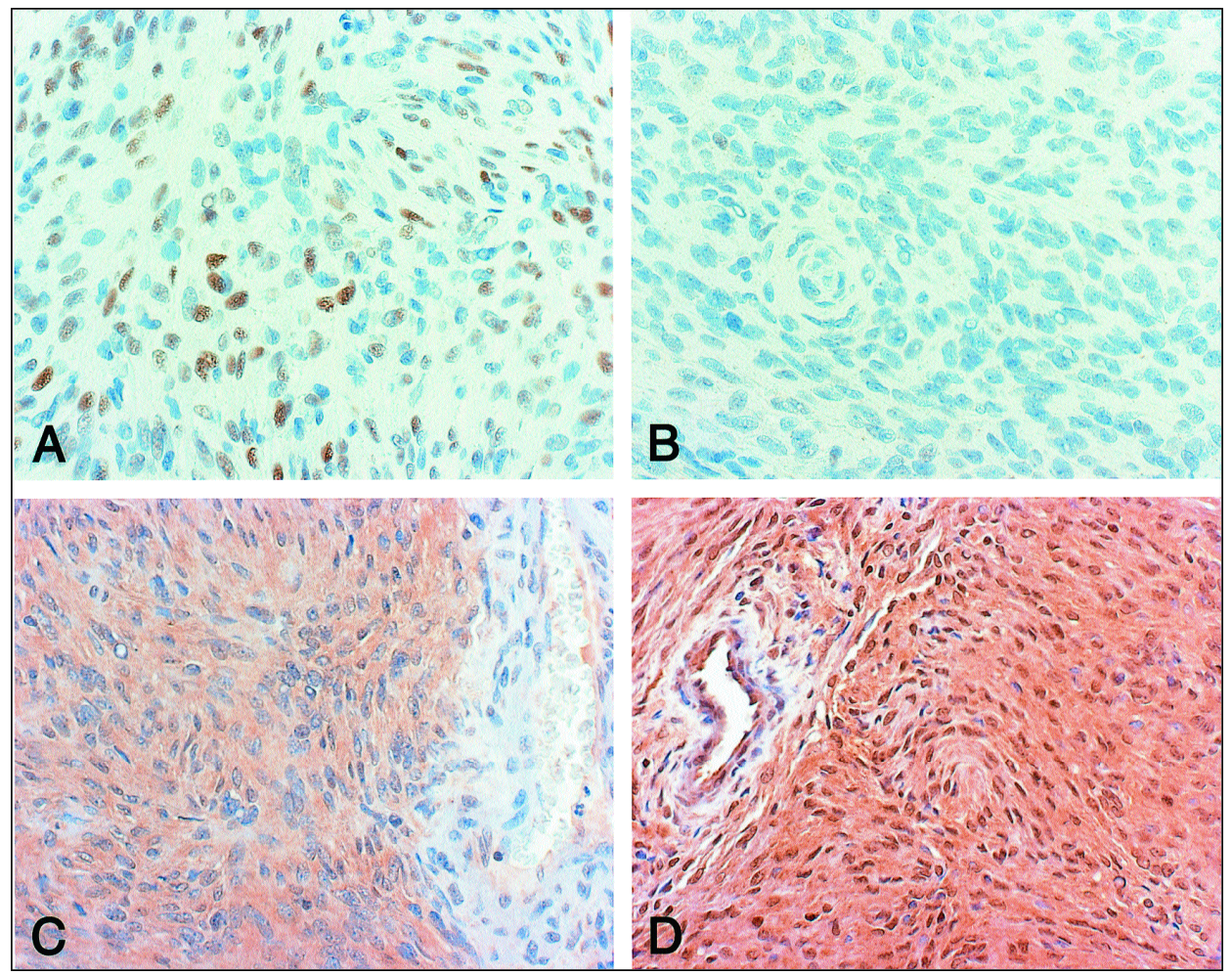

Figure 3 Immunohistochemistry (IHC) sections. (A) IHC for progesterone receptors revealing a tissue region with positive nuclei $(400 X)$. (B) IHC for estrogen receptors showing no nuclei $(400 X)$. (C) and (D) IHC for PDGFR and FGFR-2, respectively, demonstrating diffuse staining in the cytoplasm of meningioma cells (400X). 
repeat MRI scan showed a significant decrease in size of the right frontal lesion and loss of the cystic characteristics. The lesion appeared as a solidly-enhancing mass and now appeared to have a dural base, whereas before it had appeared to be intraparenchymal (Figure 1C \& 1D).

Excisional biopsy of the lesion was performed without complication. Intra-operatively, a good subarachnoid plane was identified, no invasion of cortex was evident, and a complete gross total resection of the tumour was obtained. The postoperative course was unremarkable. Final pathology of the lesion was atypical meningioma, grade II (WHO). At last follow-up the patient continued to have a normal neurologic examination and to remain seizure free.

\section{MATERIALS AND METHODS}

\section{Tumour Tissue and Pathology Review}

Tumour tissue was obtained at the time of surgery, fixed in formalin, and embedded in paraffin blocks. Sections measuring $5-\mu \mathrm{m}$ were obtained from each paraffin block and affixed to glass slides. These sections were used for hematoxylin and eosin (H\&E) staining to confirm histopathological diagnosis and for immunohistochemical analyses.

\section{Immunohistochemistry}

Paraffin embedded sections were deparaffinized and hydrated through a series of graded alcohol washes. The sections were trypsinized in a $37^{\circ} \mathrm{C}$ water bath to unmask antigens and subsequently washed in phosphate buffered saline (PBS). Endogenous peroxidase activity was blocked with $3 \%$ hydrogen peroxidase. Avidin and biotin activity were blocked using a commercially available kit (DAKO; Carpinteria, CA). Sections were washed in PBS after each blocking. Slides were then incubated with one of the following: EGFR mouse monoclonal antibody (GR01, Oncogene Research Products; Boston, MA), PDGFRB mouse monoclonal antibody (sc-339, Santa Cruz Biotechnology; Santa Cruz, Ca), FGFR-2 mouse monoclonal antibody (sc-6930, Santa Cruz Biotechnology), hPL rabbit polyclonal antibody (A0137, DAKO), PR mouse monoclonal antibody (PgR 636, DAKO), or ER mouse monoclonal antibody (1D5, DAKO). Antibody dilutions, incubation time, and incubation temperature were as follows: EGFR (1:200, overnight, $\left.4^{\circ} \mathrm{C}\right)$, PDGFRB (1:200, overnight, $\left.4^{\circ} \mathrm{C}\right)$, FGFR-2 $\left(1: 100\right.$, overnight, $\left.4^{\circ} \mathrm{C}\right)$, hPL $(1: 10,000,30$ hours, room temperature), PR (1:800, overnight, $\left.4^{\circ} \mathrm{C}\right)$, and $\operatorname{ER~}(1: 150$, overnight, $4^{\circ} \mathrm{C}$ ). Tumour sections were incubated overnight with primary antibody at $4^{\circ} \mathrm{C}$. Sections were then washed with PBS and incubated with secondary biotinylated linker antibody (LSAB+ Kit, DAKO), followed by incubation with horseradish peroxidase conjugated streptavidin (DAKO). Antibody was then detected using 3'3 Diaminobenzine (DAB Kit, Zymed; South San Francisco, CA). Slides were washed, counterstained with Gills \#1 hematoxylin and nuclei were blued in PBS. For negative controls, adjacent corresponding sections were incubated without primary antibody. Positive controls were selected for each specimen as follows: EGFR (glioblastoma multiforme specimen with previously demonstrated EGFR gene amplification), PDGFRB (colon carcinoma specimen with previously demonstrated overexpression of PDGFRB), FGFR-2 (breast cancer specimen with known overexpression of FGFR2), PR (breast cancer specimen with known overexpression of PR), ER (breast cancer specimen with known overexpression of $\mathrm{ER}$ ), and hPL (human placenta tissue).

MIB-1 staining index was determined using MIB-1 antibody (Immunotech; Coulter-Beckman-Brea, CA) at 1:500 dilution using standard methodology. The sections were reviewed and scored by a neuropathologist (AB). MIB-1 staining index (PCI $\%$ ) was defined as the number of MIB-1 positive cells divided by the total number of cells (1000), multiplied by 100; 1344 cells were counted.

\section{RESUlTS \\ Pathology}

Gross inspection of the resected lesion demonstrated an ovoid, tan, rubbery, solid mass measuring $1.5 \times 1.7 \times 1.2 \mathrm{~cm}$. Paraffin-embedded sections stained with $\mathrm{H} \& \mathrm{E}$ revealed a meningioma with increased cellularity and frequent mitoses (mitotic index $=5$ mitoses $/ 10$ high-power fields) (Figure 2). Necrosis was not present. Based on these findings, the final diagnosis was atypical fibroblastic meningioma grade II (WHO).

\section{Immunohistochemistry}

Approximately $25 \%$ of nuclei stained positive with PR antibody (Figure 3A), with the degree of staining and number of positive nuclei varying by tissue area. There was a trace amount

Table: Summary of pregnancy-associated meningioma reports with receptor analysis.*

\begin{tabular}{|c|c|c|c|c|c|c|}
\hline Study & $\begin{array}{l}\text { Patient Age } \\
\text { (yrs) }\end{array}$ & $\begin{array}{l}\text { Weeks } \\
\text { Gestation }\end{array}$ & Patient Presentation & Tumour Location & $\begin{array}{l}\text { Progesterone } \\
\text { Receptors }\end{array}$ & $\begin{array}{l}\text { Estrogen } \\
\text { Receptors }\end{array}$ \\
\hline Giannini et $\mathrm{al}^{21}$ & 30 & 25 & vertigo, ataxia & CPA & positive & negative \\
\hline Goldberg et $\mathrm{al}^{23}$ & 34 & 28 & HA, confusion, emesis & frontal lobe & $111 \mathrm{fmol} / \mathrm{mg}$ & $0 \mathrm{fmol} / \mathrm{mg}$ \\
\hline Isla et $\mathrm{al}^{20}$ & NA & NA & NA & $\mathrm{NA}$ & $84 \mathrm{fmol} / \mathrm{mg}$ & $16 \mathrm{fmol} / \mathrm{mg}$ \\
\hline Ismail et al $^{23}$ & 36 & 31 & focal seizure & parietal lobe & positive & negative \\
\hline Old et $\mathrm{al}^{24}$ & 24 & NA & focal seizure & parasagittal & positive & negative \\
\hline Pliskow et $\mathrm{al}^{25}$ & 28 & 21 & HA, TC seizure & frontal-parietal lobes & positive & negative \\
\hline Saitoh et $\mathrm{al}^{26}$ & 31 & NA & HA, vertigo, nausea & frontal lobe & $15 \mathrm{fmol} / \mathrm{mg}$ & $12 \mathrm{fmol} / \mathrm{mg}$ \\
\hline Smith et al** & 33 & 39 & focal seizure & frontal lobe & positive & trace \\
\hline
\end{tabular}

$* \mathrm{NA}=$ not available, $\mathrm{HA}=$ headache, $\mathrm{CPA}=$ cerebellopontine angle, $\mathrm{TC}=$ tonic clonic, $* *$ Present case report 
of ER staining (Figure 3B). Platelet-derived growth factor receptor B and FGFR-2 antibody staining was diffusely and strongly positive in a cytoplasmic pattern. (Figures 3C and 3D). The degree of staining for each of these antibodies was of similar intensity throughout the tissue sections examined. Immunohistochemistry for EGFR and hPL was negative. Corresponding positive and negative controls for each antibody were appropriately positive and negative, respectively. The MIB-1 PCI\% was 2.8 .

\section{DISCUSSION}

We describe the presentation of a meningioma in the immediate postpartum period with subsequent rapid decrease in the size prior to any intervention. Using surgically resected tumour tissue, we have characterized the level of expression of several growth factors associated with pregnancy, including PR, ER, PDGFRB, FGFR-2, EGFR, and hPL.

The association between pregnancy and meningioma has attracted the attention of multiple investigators, although the exact relationship and the underlying mechanisms remain to be clarified. Review of the literature by Roelvink and coworkers ${ }^{18}$ identified 28 cases of intracranial meningioma with initial presentation during pregnancy or within one week postpartum. Most of these reports focused on clinical presentation and management of this often complicated situation with only a limited number providing characterization of the tumour tissue (Table) and even fewer reports providing complete imaging data. Of the 25 patients with initial presentation during pregnancy, postpartum amelioration of symptoms within one week of delivery was identified in $48 \% .^{18}$ Importantly, since the incidence of meningioma does not increase significantly during pregnancy, these studies do not suggest a causal relationship between pregnancy and meningioma, but rather an increased frequency of symptomatic presentation during pregnancy.

The mechanism underlying pregnancy associated increase in meningioma size and peritumoural edema has not been well defined. Since meningiomas frequently express steroid receptors, it has been hypothesized that hormonal influences may be involved in the increase in tumour size by increasing blood volume and extracellular and intracellular fluid, as well as by increasing growth and proliferation of the tumour tissue..$^{5,18,19}$ An apparent correlation between the blood progesterone level and the manifestation of intracranial tumours has been suggested, although a definitive causal relationship has not yet been established. ${ }^{18}$ Thus, it may be hypothesized that the decline in progesterone levels following delivery may contribute to a decrease in tumour volume and pertitumoural edema and account for clinical regression. However, since the symptomatic appearance of meningiomas during pregnancy is primarily confined to the second and third trimesters, it is unlikely that only progesterone is involved. ${ }^{18,20}$

The present case demonstrated immunostaining for PR and ER on approximately $25 \%$ and a trace number of tumour nuclei, respectively. This is consistent with previous assessments of meningiomas associated with pregnancy, in which PR are consistently present and ER are minimally present or absent (Table). ${ }^{20-26}$ These receptors have also been studied in meningiomas not associated with pregnancy. Progesterone receptor and ER have been demonstrated in approximately twothirds and $10 \%$ of these cases, respectively. ${ }^{27}$

The role of $\mathrm{PR}$ in the development of meningiomas is supported by several observations. In order to be biologically active, these receptors need to be located in the nucleus. In the majority of reported cases, including the present, PR are located in the nucleus where they are able to induce specific transcription. ${ }^{12}$ In addition, PR expression is very low in normal meninges, suggesting that its increased expression is associated with meningioma tumourigenesis. ${ }^{28}$ There are several observations that suggest that PR are more important in lowgrade than in high-grade meningiomas. There are, however, several observations that contradict the importance of progesterone in meningiomas. Progesterone receptors are more common in grade I meningiomas than in grade III meningiomas, occurring in $90 \%$ and $25 \%$ of these tumours, respectively. ${ }^{11,14}$ Furthermore, there is an inverse correlation between the degree of PR expression and mitotic index. ${ }^{14}$ Thus, these data implicate $\mathrm{PR}$ in the growth of grade I meningiomas but suggest that other factors may be more important in anaplastic meningiomas.

Fibroblast growth factors are potent angiogenic factors and are mitogenic toward cells derived from neuroectoderm and mesoderm. ${ }^{29,30}$ Expression of fibroblastic growth factor has been demonstrated in up to $90 \%$ of meningiomas ${ }^{31-33}$ and expression of FGFR-1 (FLG) and FGFR-2 (BEK) have been demonstrated in the majority of meningiomas. ${ }^{32}$ Whether the fibroblast growth factor system is associated with meningiomas that present during pregnancy has not been established. The present case demonstrated staining for FGFR-2 on essentially all tumour cells visualized, consistent with fibroblast growth factors serving a growth factor role.

Expression of platelet-derived growth factor $\mathrm{BB}$ and PDGFRB has been shown in the majority of meningiomas studied, and the presence of an autocrine stimulatory loop has been suggested. ${ }^{34-36}$ The activity of the PDGF system has not been established in meningiomas that present during pregnancy. The present case demonstrated PDGFRB antibody staining on essentially all tumour cells examined.

A report by Boyle-Walsh and coworkers ${ }^{37}$ demonstrated a growth-stimulatory effect of hPL on human meningioma cells in vitro. This observation, coupled with the increased levels of hPL observed in the second and third trimester of pregnancy, led the authors to speculate a growth-stimulatory role of hPL on meningioma cells in vivo. The present case did not demonstrate specific binding for hPL, making it unlikely that it had a role in this case.

Epidermal growth factor expression has been detected in $40 \%-100 \%$ of meningiomas investigated ${ }^{38,39}$ but is only present in trace amounts in normal CNS tissue. The present case did not demonstrate specific binding for EGFR antibodies, suggesting that the growth promoting factors for this tumour do not include epidermal growth factor.

Our understanding of the factors involved in the development and proliferation of meningiomas is evolving. Although the majority of meningiomas may be cured surgically, a significant subset exhibit aggressive behavior or have a complex location that precludes surgical cure. At present, radiation therapy is the only proven adjuvant therapy for meningioma. Development of additional adjuvant therapies would facilitate nonsurgical 
management of meningiomas. The association of increased meningioma growth with pregnancy may ultimately provide important insight into the growth factors responsible for meningioma proliferation. The present report documents such a case, both clinically and radiographically, and provides the most extensive growth factor profile reported to date for such a tumour.

\section{REFERENCES}

1. Longstreth WT, Dennis LK, McGuire VM, Drangsholt MT, Koepsell TD. Epidemiology of intracranial meningioma. Cancer 1993; 72: 639-648.

2. Stafford SL, Perry A, Suman VJ, et al. Primarily resected meningiomas: outcome and prognostic factors in 581 Mayo Clinic patients, 1978 through 1988. Mayo Clin Proc 1998; 73: 936-942.

3. Bickerstaff ER, Small JM, Guest IA. The relapsing course of certain meningiomas in relation to pregnancy and menstruation. J Neurol Neurosurg Psychiatry 1958; 21: 89-91.

4. Black PML. Hormone, radiosurgery and virtual reality: new aspects of meningioma management. Can J Neurol Sci 1997; 24: 302306

5. Benzel EC, Gelder FB. Correlation between sex hormone binding and peritumoural edema in intracranial meingiomas. Neurosurgery 1988; 23: 169-174.

6. DeGrood RM, Beemer WH, Fenner DE, Compton AA. A large meningioma presenting as a neurologic emergency in late pregnancy. Obstet Gynecol 1987; 69: 439-440.

7. Kempers RD, Miller RH. Management of pregnancy associated with brain tumours. Am J Obstet Gynecol 1963; 87: 858-864.

8. Schlehofer B, Blettner M, Wahrendorf J. Association between brain tumours and menopausal status. J Natl Cancer Inst 1992; 84: $1346-1349$

9. Helseth A, Mork SJ, Glattre E. Neoplasms of the central nervous system in Norway. V, meningioma and cancer of other sites. An analysis of the occurrence of multiple primary neoplasms in meningioma patients in Norway from 1955 through 1986. APMIS 1989; 97: 738-744

10. Schoenberg BS, Christine BW, Whisant JP. Nervous system neoplasms and the primary malignancies of other sites. The unique association between meningiomas and breast cancer. Neurology 1975; 28: 705-712.

11. Brandis A, Mirazi S, Tatagiba $\mathbf{M}$, et al. Immunohistochemical detection of female sex hormone receptors in meningiomas: correlation with clinical and histological features. Neurosurgery 1993; 33: 212-217.

12. Carroll RS, Zhang J, Dashner K, Black PML. Progesterone and glucocorticoid activation in meningiomas. Neurosurgery 1995; 37: 92-97.

13. Fewings PE, Battersby RD, Timperley WR. Long-term follow up of progesterone receptor status in benign meningioma: a prognostic indicator of recurrence? J Neurosurg 2000; 92: 401-405.

14. Hsu DW, Efird JT, Hedley-Whyte ET. Progesterone and estrogen receptors in meningiomas: prognostic considerations. J Neurosurg 1997; 86: 113-120.

15. Perry A, Cai DX, Scheithauer BW, et al. Merlin, DAL-1, and progesterone receptor expression in clinicopathologic subsets of meningioma: a correlative immunohistochemical study of 175 cases. J Neuropathol Exp Neurol 2000; 59: 872-879.

16. Tilzer LL, Plapp FV, Evans JP, Stone D, Alward K. Steroid receptor proteins in human meningiomas. Cancer 1982; 49: 633-636.

17. Verheijen FM, Sprong M, Jacobs GH, et al. Progesterone receptor isoform expression in human meningiomas. Eur J Cancer 2001; 37: $1488-1495$.

18. Roelvink NCA, Kamphorst W, van Alphen HAM, Rao BR. Pregnancy-related primary brain and spinal tumours. Arch Neurol 1987; 44: 209-215.
19. Philippon J, Foncin JF, Grob R, et al. Cerebral edema associated with meningiomas: Possible role of a secretory-excretory phenomenon. Neurosurgery 1984;14: 295-301.

20. Isla A, Alvarez F, Gonzalez A, et al. Brain tumour and pregnancy. Obstet Gynecol 1997; 89: 19-23.

21. Giannini A, Bricchi M. Posterior fossa surgery in the sitting position in a pregnant patient with cerebellopontine angle meningioma. $\mathrm{Br}$ J Anaesth 1999; 82: 941-944.

22. Goldberg M, Rappaport ZH. Neurosurgical, obstetric and endocrine aspects of meningioma during pregnancy. Isr J Med Sci 1987; 23: 825-828.

23. Ismail $\mathrm{K}$, Coakham HB, Walters FJ. Intracranial meningioma with progesterone positive receptors presenting in late pregnancy. Eur J Anaesthesiol 1998; 15: 106-109.

24. Old SE, Burnet NG, Macfarlane R, O'Donovan DG, Langmack K. Post-partum retreatment with iridium-192 wire brachytherapy for meningioma recurring in pregnancy. Clin Oncol 2001; 13: 114116.

25. Pliskow S, Herbst SJ, Saiontz HA, Cove H, Ackerman RT. Intracranial meningioma with positive progesterone receptors: a case report. J Reprod Med 1995; 40: 154-156.

26. Saitoh Y, Oku Y, Izumoto S, Go J. Rapid growth of a meningioma during pregnancy: relationship with estrogen and progesterone receptors. Neurol Med Chir (Tokyo) 1989; 29: 440-443.

27. Sanson M, Cornu P. Biology of meningiomas. Acta Neurochir (Wien) 2000; 142: 493-505.

28. Carroll RS, Glowacka D, Dashner K, Black PM. Progesterone receptor expression in meningiomas. Cancer Res 1993; 53: 13121326.

29. Gospodarowicz D, Ferrara N, Schweigerer L, Neufeld G. Structural characterization and biological functions of fibroblast growthfactor. Endocr Rev 1987; 8: 95-114.

30. Gross JL, Morrison RS, Eidsvoog K, et al. Basic fibroblast growthfactor - a potential autocrine regulator of human glioma cellgrowth. J Neurosci Res 1990; 27: 689-696.

31. Lamszus K, Lengler U, Dchmidt NO, et al. Vascular endothelial growth factor, hepatocyte growth factor/scatter factor, basic fibroblast growth factor in human meningiomas and their relation to angiogenesis and malignancy. Neurosurgery 2000; 46: 938948.

32. Takahashi JA, Suzui H, Yasuda Y, et al. Gene expression of fibroblast growth factor receptors in the tissues of human gliomas and meningiomas. Biochem Biophys Res Commun 1991; 177: 17.

33. Takahashi JA, Mori H, Fukumoto M, et al. Gene expression of fibroblast growth factors in human gliomas and meningiomas: demonstration of cellular or basic fibroblast growth factor mRNA and peptide in tumour tissue. Proc Natl Acad Sci USA1990; 87: 5710

34. Black PML, Carroll R, Glowacka D, Riley K, Dashner K. Plateletderived growth factor expression and stimulation in human meningiomas. J Neurosurg 1994; 81: 388-393.

35. Maxwell M, Galanopoulos T, Hedley-Whyte ET, Black PML, Antoniades HN. Human meningiomas co-express plateletderived growth factor (PDGF) and PDGF-receptor genes and protein products. Int J Cancer 1990; 46: 16-21.

36. Yang SY, Xu GM. Expression of PDGF and its receptor as well as their relationship to proliferating activity and apoptosis of meningiomas in human meningiomas. J Clin Neurosci 2000; 8: 49-53.

37. Boyle-Walsh E, Shenkin A, White MC, Fraser WD. Effect of glycoprotein and protein hormones on human meningioma cell proliferation in vitro. J Endocrinol 1995; 145: 155-161.

38. Carroll RS, Black PML, Zhang J, et al. Expression and activation of epidermal growth factor receptors in meningiomas. J Neurosurg 1997; 87: 315-323.

39. Jones NR, Rossi ML, Gregoriou M, Hughes JT. Epidermal growth factor receptor expression in 72 meningiomas. Cancer 1990; 66: $152-155$. 